\title{
Psychological Predictors of Satisfaction after Lumbar Surgery for Lumbar Spinal Stenosis
}

\author{
Yoshio Yamamoto ${ }^{1}$, Mamoru Kawakami ${ }^{1,2}$, Masakazu Minetama ${ }^{1}$, Masafumi Nakagawa ${ }^{1}$, \\ Masatoshi Teraguchi ${ }^{1}$, Ryohei Kagotani ${ }^{1}$, Yoshimasa Mera ${ }^{1}$, Tadashi Sumiya ${ }^{1}$, \\ Sachika Matsuo ${ }^{1}$, Tomoko Kitano ${ }^{1}$, Yukihiro Nakagawa ${ }^{1}$ \\ ${ }^{1}$ Spine Care Center, Wakayama Medical University Kihoku Hospital, Wakayama, Japan \\ ${ }^{2}$ Department of Orthopaedic Surgery, Saiseikai Wakayama Hospital, Wakayama, Japan
}

Study Design: A retrospective study of prospectively collected clinical data.

Purpose: To identify preoperative psychological factors associated with patient satisfaction after surgery for lumbar spinal stenosis (LSS).

Overview of Literature: Associations between depressive symptoms, anxiety, and worse surgical outcome or patient dissatisfaction have been reported in LSS patients. However, the influence of preoperative pain catastrophizing and fear-avoidance beliefs on postoperative satisfaction is not well understood.

Methods: LSS patients who underwent decompression surgery with or without fusion were included. Clinical outcomes were measured before surgery and 6 months postoperatively using the Zurich Claudication Questionnaire (ZCQ); Visual Analog Scale (VAS) of low back pain, leg pain, and leg numbness; Japanese Orthopaedic Association Back Pain Evaluation Questionnaire; and the Medical Outcomes Study 36-item Short-Form General Health Survey (SF-36). The Hospital Anxiety and Depression Scale (HADS), Pain Catastrophizing Scale, and Pain Anxiety Symptoms Scale were used to evaluate psychological status before surgery. Patients were classified as satisfied or dissatisfied with surgery based on a ZCQ satisfaction subscale cutoff score of 2.5 .

Results: The satisfied and dissatisfied groups contained 128 and 29 patients, respectively. Six months postoperatively, outcome scores for the dissatisfied group were unchanged or worse than preoperative scores $(p>0.05)$. Multivariate logistic regression analysis showed significant associations between dissatisfaction and preoperative low back pain VAS score $\geq$ median (odds ratio [OR], 0.27; $95 \%$ confidence interval [CI], $0.10-0.74 ; p=0.01)$, preoperative mental health SF-36 score $\geq$ median $(0 \mathrm{R}, 0.26 ; 95 \% \mathrm{Cl}, 0.08-0.89$; $p=0.03$ ), and preoperative anxiety HADS score $\geq$ median (OR, 3.95; 95\% Cl, 1.16-13.46; $p=0.03$ ).

Conclusions: Preoperative less severe low back pain, lower mental health, and higher anxiety are associated with patient dissatisfaction with lumbar surgery, not depression, pain catastrophizing, or fear-avoidance beliefs. Pre- and postoperative psychological status should be assessed carefully and managed appropriately.

Keywords: Spinal stenosis; Depression; Anxiety; Catastrophization; Fear

Received Jul 9, 2020; Revised Sep 28, 2020; Accepted Oct 27, 2020

Corresponding author: Yoshio Yamamoto

Spine Care Center, Wakayama Medical University Kihoku Hospital, 219 Myoji, Katsuragi-cho, Ito-gun, Wakayama 649-7113, Japan

Tel: +81-736-22-0066, Fax: +81-736-22-2579, E-mail: yoshio@wakayama-med.ac.jp 


\section{Introduction}

Lumbar spinal stenosis (LSS) is a condition in which there is diminished space available for neural and vascular elements in the lumbar spine secondary to degenerative changes in the spinal canal. These changes can cause pain in the legs and back as well as impaired ambulation and other disabilities [1]. LSS is the most common indication for spine surgery in people older than 65 years [2]. Surgery for patients who remain severely symptomatic after a course of conservative treatment is generally considered the gold standard [1]. However, one-third of patients are not satisfied with the outcome because of residual leg and back pain, inferior function, and poor health-related quality of life $[3,4]$. Therefore, identification of prognostic factors that can aid in patient selection is important.

Several predictors of patient satisfaction and outcome after LSS surgery have been identified. Poor satisfaction is associated with a predominance of back (as opposed to leg) pain, longer duration of back and leg pain, higher level of pain, worse preoperative functional status, smoking, obesity, previous spine surgery, and greater medical comorbidity [4-7]. Outcome predictors include low back pain frequency, leg numbness, symptom duration, preoperative function and quality of life, smoking, obesity, cardiovascular comorbidity, and disorders that influence walking ability [3,6-9].

Psychological status before surgery is believed to influence spine surgery outcome and postoperative satisfaction. The fear-avoidance model is widely used to explain the effect of psychological factors on pain experience and development of chronic pain and disability [10]. According to the model, negative beliefs about pain and/or negative perceptions about illness lead to a catastrophizing response in which the worst possible outcome is imagined. This type of response causes anxiety, fear, and subsequent fear of activity and avoidance, which in turn can lead to disuse, disability, and depression. Associations between depressive symptoms, anxiety, and worse surgical outcome or patient dissatisfaction have been previously reported in LSS patients [11-14]. However, the influence of preoperative pain catastrophizing and fear-avoidance beliefs on postoperative satisfaction is not well understood [14-17]. The purpose of this study was to identify preoperative psychological factors associated with patient satisfaction after LSS surgery. We hypothesized that preoperative psychological factors, including depression, anxiety, pain catastrophizing, and fear-avoidance beliefs, are associated with patient satisfaction.

\section{Materials and Methods}

\section{Study design and population}

This retrospective study of prospectively collected data received approval of the institutional review board of Wakayama Medical University (no., 2728). The requirement for informed consent from individual patients was omitted because of the retrospective design of this study. LSS patients who underwent decompression surgery with or without fusion at the Spine Care Center, Wakayama Medical University Kihoku Hospital between April 2015 and March 2019 and met the following criteria were included the presence of neurogenic intermittent claudication and leg pain and/or numbness with or without low back pain, radiographic evidence of dural sac or nerve root compression caused by degenerative changes, and a history of an ineffective response to nonsurgical treatment for more than 3 months. We excluded patients who had previous spinal surgery, foraminal or extraforaminal stenosis, degenerative scoliosis, cognitive impairment, or a history of psychiatric illness. One hundred eighty-five patients met the inclusion criteria and 157 (84.9\%) completed the 6-month outcome assessment.

\section{Measurements}

Clinical outcomes were measured preoperatively and 6 months postoperatively using the following instruments: Zurich Claudication Questionnaire (ZCQ) [18]; Visual Analog Scale (VAS) of low back pain, leg pain, and leg numbness; Japanese Orthopaedic Association Back Pain Evaluation Questionnaire (JOABPEQ) [19]; and Medical Outcomes Study 36-item Short-Form General Health Survey (SF-36) [20]. The Hospital Anxiety and Depression Scale (HADS) [21], Pain Catastrophizing Scale (PCS) [22], and Pain Anxiety Symptoms Scale (PASS-20) [23] were used to evaluate psychological status before surgery. All questionnaires were administered by an author who was not involved in surgical treatment or postoperative care.

The HADS is a self-assessed questionnaire comprising a 14-item scale with seven items that measure anxiety and seven that measure depression. The scores range from 0 to 21 for each subscale, with higher scores indicating greater 
distress [21]. The PCS is a 13-item self-reported measure that assesses catastrophic thoughts and feelings about pain. It comprises three subscales: rumination, magnification, and helplessness. The PCS score ranges from 0 to 52, with higher scores indicating higher levels of catastrophic thoughts and feelings about pain [22]. The PASS-20 is a 20 -item self-reported measure that assesses pain-related anxiety and fear responses. The scale contains four subscales: cognitive anxiety, escape/avoidance behaviors, fear of pain, and physiological symptoms of anxiety. The total score ranges from 0 to 100 , with higher scores indicating greater pain-related anxiety and fear responses [23].

Stenosis severity was graded using a seven-grade classification based on dural sac morphology on axial T2 magnetic resonance imaging (MRI) of the lumbar spine [24]. The magnitude of the surgical procedure was assessed using a surgical invasiveness index [25].

\section{Statistical analysis}

Using a cutoff value of 2.5 for the ZCQ satisfaction subscale to indicate a successful outcome, patients were classified into two groups, satisfied and dissatisfied. Preoperative scores and mean score change 6 months after surgery were compared between the two groups. Pearson's chisquare test was used to compare categorical data. Parametric variables were compared using the Student $t$-test and nonparametric variables were compared using the Mann-Whitney $U$-test. Intragroup changes in repeated measures were analyzed using the paired $t$-test or Wilcoxon signed-rank test as appropriate.

Binary logistic regression using the forward stepwise likelihood ratio method were used to identify preoperative factors independently associated with satisfaction on the 6-month ZCQ subscales. The following preoperative independent variables were included: age (years), sex (male: no/yes), body mass index (BMI) $\left(\mathrm{kg} / \mathrm{m}^{2}\right)$, duration of symptoms (months), presence of comorbidities (no/yes), smoking status (no/yes), surgical procedure (fusion: no/ yes), and ZCQ, VAS, JOABPEQ, SF-36, HADS, PCS, and PASS-20 scores (equal to or greater than the median: no/ yes). We also included predominance of back pain (VAS back pain over VAS leg pain: no/yes). The satisfaction score on the ZCQ subscale was dichotomized as satisfied $(\leq 2.5)$ or dissatisfied $(>2.5)$ as the dependent variable. To test logistic model quality, the Hosmer-Lemeshow goodness-of-fit test and Nagelkerke's $R^{2}$ were used. A $p>0.05$ indicated a good model fit in the Hosmer-Lemeshow goodness-of-fit test. All statistical tests were two-tailed, and the significance level was fixed at 0.05 throughout. All analyses were performed using IBM SPSS software ver. 25.0 (IBM Corp., Armonk, NY, USA).

\section{Results}

A total of 157 patients ( 84 men and 73 women; average age, 69.8 years) who completed the 6 -month postoperative assessment were classified. The satisfied group included 128 patients (70 men and 58 women; average age, 69.7 years), and the dissatisfied group included 29 (14 men and 15 women; average age, 70.2 years).

Patient age, sex distribution, BMI, symptom duration, MRI findings, surgical procedure (with or without fusion), and number of levels decompressed did not differ significantly between the groups $(p \geq 0.05)$ (Tables 1,2$)$. However, the dissatisfied group had worse baseline scores for several parameters: mental health $(59.6 \pm 21.3$ points versus $47.0 \pm 16.2$ points) and general health $(50.0 \pm 14.7$ points versus $42.8 \pm 16.8$ points) on the SF- 36 ; anxiety (5.2 \pm 3.5 points versus $7.6 \pm 3.0$ points) and depression (5.3 \pm 3.6 points versus $7.0 \pm 3.7$ points) on the HADS; and magnification ( $5.9 \pm 3.1$ points versus $7.3 \pm 2.8$ points) on the PCS (all $p<0.05$ ) (Table 1).

Six months after surgery, the satisfied group showed significantly greater improvements in all outcome measures on the SF-36 subscales except for general health $(p<0.05)$ (Table 3). Outcome scores for the dissatisfied group at 6 months were unchanged (Table 3). Bone union rate did not differ between the groups (satisfied group, $81.3 \%$; dissatisfied group, $62.5 \%$; $p=0.10$ ).

Stepwise multivariate logistic regression showed significant associations between dissatisfaction and preoperative low back pain VAS score $\geq$ median (odds ratio [OR], 0.27; 95\% confidence interval $[\mathrm{CI}], 0.10-0.74 ; p=0.01$ ), preoperative mental health SF-36 score $\geq$ median (OR, 0.26 ; $95 \%$ CI, $0.08-0.89 ; p=0.03$ ), and preoperative anxiety HADS score $\geq$ median (OR, 3.95; 95\% CI, 1.16-13.46; $p=0.03$ ) (Table 4).

\section{Discussion}

This study showed that compared to satisfied patients, dissatisfied ones had poorer mental and general health before surgery as well as higher levels of anxiety, depres- 
Table 1. Comparison of clinical characteristics between satisfied and dissatisfied groups at the baseline

\begin{tabular}{|c|c|c|c|}
\hline Characteristic & $\begin{array}{c}\text { Satisfied } \\
\text { group }(n=128)\end{array}$ & $\begin{array}{l}\text { Dissatisfied } \\
\text { group }(n=29)\end{array}$ & $p$-value \\
\hline Age (yr) & $69.7 \pm 8.1$ & $70.2 \pm 10.2$ & $0.79^{\mathrm{al}}$ \\
\hline Sex & & & $0.53^{b)}$ \\
\hline Female & 58 & 15 & \\
\hline Male & 70 & 14 & \\
\hline Body mass index $\left(\mathrm{kg} / \mathrm{m}^{2}\right)$ & $24.1 \pm 23.1$ & $23.9 \pm 2.6$ & $0.79^{\mathrm{a})}$ \\
\hline \multicolumn{4}{|l|}{ Comorbidities (\%) } \\
\hline Hypertension & $87(68.0)$ & $21(72.4)$ & $0.64^{b /}$ \\
\hline Diabetes & $25(19.5)$ & $9(31.0)$ & $0.17^{b)}$ \\
\hline Heart disease & $14(10.9)$ & $3(10.3)$ & $0.93^{b /}$ \\
\hline Pulmonary disease & $6(4.7)$ & $0(0)$ & $0.23^{b)}$ \\
\hline Smoker & $13(10.2)$ & $5(17.2)$ & $0.28^{b)}$ \\
\hline Duration of symptoms (mo) & $7.7 \pm 8.0$ & $9.8 \pm 11.6$ & $0.12^{c 1}$ \\
\hline $\begin{array}{l}\text { Moderate or severe stenotic } \\
\text { levels }(\%)\end{array}$ & & & $0.30^{\mathrm{bl}}$ \\
\hline 0 & $21(16.4)$ & $4(13.8)$ & \\
\hline 1 & $50(39.1)$ & $10(34.5)$ & \\
\hline 2 & $40(31.3)$ & $7(24.1)$ & \\
\hline$\geq 3$ & $17(13.3)$ & $8(27.6)$ & \\
\hline No. of decompressions & $3.1 \pm 1.8$ & $3.1 \pm 1.1$ & $0.96^{\mathrm{a})}$ \\
\hline Fusion surgery (\%) & $80(62.5)$ & $16(55.2)$ & $0.47^{b)}$ \\
\hline Invasiveness index & $9.5 \pm 6.1$ & $9.2 \pm 5.8$ & $0.93^{c)}$ \\
\hline \multicolumn{4}{|l|}{ ZCO } \\
\hline Symptom severity & $3.5 \pm 0.6$ & $3.6 \pm 0.6$ & $0.74^{a)}$ \\
\hline Physical function & $2.6 \pm 0.6$ & $2.8 \pm 0.5$ & $0.17^{c)}$ \\
\hline \multicolumn{4}{|l|}{ VAS } \\
\hline Back pain & $61.1 \pm 28.5$ & $55.8 \pm 22.7$ & $0.27^{c)}$ \\
\hline Leg pain & $68.9 \pm 25.3$ & $67.0 \pm 18.4$ & $0.33^{c)}$ \\
\hline Leg numbness & $62.3 \pm 28.8$ & $66.2 \pm 25.0$ & $0.66^{c)}$ \\
\hline \multicolumn{4}{|l|}{ JOABPEO } \\
\hline Pain-related disorders & $42.0 \pm 32.4$ & $47.9 \pm 35.8$ & $0.39^{c l}$ \\
\hline Lumbar dysfunction & $57.4 \pm 28.7$ & $55.1 \pm 23.9$ & $0.50^{c)}$ \\
\hline Gait disturbance & $31.6 \pm 24.0$ & $28.7 \pm 22.3$ & $0.61^{c)}$ \\
\hline Social life dysfunction & $35.5 \pm 20.9$ & $37.9 \pm 18.7$ & $0.37^{\mathrm{cl}}$ \\
\hline Psychological disorders & $45.2 \pm 16.4$ & $40.1 \pm 20.0$ & $0.10^{c)}$ \\
\hline \multicolumn{4}{|l|}{ SF-36 } \\
\hline Physical functioning & $44.8 \pm 22.9$ & $44.1 \pm 21.1$ & $0.84^{c l}$ \\
\hline Bodily pain & $30.9 \pm 15.6$ & $27.9 \pm 12.7$ & $0.24^{c)}$ \\
\hline Role physical & $40.6 \pm 25.4$ & $39.1 \pm 26.2$ & $0.92^{c \mid}$ \\
\hline Role emotional & $49.0 \pm 30.8$ & $37.2 \pm 24.0$ & $0.08^{c)}$ \\
\hline Mental health & $59.6 \pm 21.3$ & $47.0 \pm 16.2$ & $0.01^{\mathrm{cl}}$ \\
\hline
\end{tabular}

Table 1. Continued

\begin{tabular}{|lccc|}
\hline Characteristic & $\begin{array}{c}\text { Satisfied } \\
\text { group }(n=128)\end{array}$ & $\begin{array}{c}\text { Dissatisfied } \\
\text { group }(n=29)\end{array}$ & $p$-value \\
\hline Social functioning & $61.2 \pm 28.1$ & $57.1 \pm 21.9$ & $0.34^{\text {c) }}$ \\
\hline Vitality & $49.1 \pm 22.0$ & $40.6 \pm 19.4$ & $0.06^{\text {a) }}$ \\
\hline General health & $50.0 \pm 14.7$ & $42.8 \pm 16.8$ & $0.02^{\text {a) }}$ \\
\hline HADS & & & \\
\hline Depression & $5.3 \pm 3.6$ & $7.0 \pm 3.7$ & $0.03^{\text {c) }}$ \\
\hline Anxiety & $5.2 \pm 3.5$ & $7.6 \pm 3.0$ & $0.00^{\text {c) }}$ \\
\hline PCS total & $31.0 \pm 10.9$ & $34.3 \pm 11.5$ & $0.08^{\text {c) }}$ \\
\hline Rumination & $15.2 \pm 4.1$ & $16.3 \pm 4.6$ & $0.05^{\text {c) }}$ \\
\hline Helplessness & $9.9 \pm 5.0$ & $10.7 \pm 5.4$ & $0.30^{\text {c) }}$ \\
\hline Magnification & $5.9 \pm 3.1$ & $7.3 \pm 2.8$ & $0.01^{\text {c) }}$ \\
\hline PASS-20 & $42.3 \pm 18.1$ & $43.9 \pm 14.3$ & $0.68^{\text {a) }}$ \\
\hline Cognitive anxiety & $12.7 \pm 6.1$ & $13.2 \pm 4.8$ & $0.71^{\text {a) }}$ \\
\hline Escape/avoidance & $11.9 \pm 4.7$ & $12.3 \pm 4.1$ & $0.74^{\text {a) }}$ \\
\hline Fear & $11.7 \pm 6.1$ & $12.2 \pm 4.8$ & $0.70^{\text {a) }}$ \\
\hline Physiological anxiety & $5.9 \pm 4.2$ & $6.2 \pm 3.8$ & $0.55^{\text {c) }}$ \\
\hline
\end{tabular}

Values are presented as mean \pm standard deviation or number (\%). ZCQ, Zurich Claudication Questionnaire; VAS, Visual Analog Scale; JOABPEQ, Japanese Orthopaedic Association Back Pain Evaluation Questionnaire; SF-36, Medical Outcomes Study 36-Item Short-Form General Health Survey; HADS, Hospital Anxiety and Depression Scale; PCS, Pain Catastrophizing Scale; PASS20, Pain Anxiety Symptoms Scale.

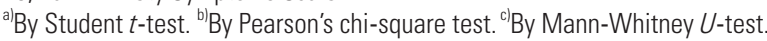

sion, and magnification. Dissatisfied patients showed no improvement in pain, disability, or quality of life outcome measures 6 months after surgery. Multiple regression analysis showed that less severe low back pain, poorer mental health, and higher anxiety levels before surgery were associated with dissatisfaction with surgery.

Although the dissatisfied group had higher levels of depression and anxiety before surgery than the satisfied group, only anxiety was a significant prognostic factor for patient satisfaction in multivariate analysis. Associations between depressive symptoms/anxiety and worse surgical outcome/satisfaction have been previously reported in LSS patients, although less data have been reported for anxiety [11-14]. However, other studies have found that depression is not associated with postoperative disability or quality of life [26,27]. Wagner et al. [27] reported a significant reduction in the percentage of patients with pathological depression scores during follow-up after decompression surgery for degenerative lumbar spine disease. They also found that the EuroQoL-5 Dimension and Oswestry Disability Index (ODI) mean scores improved 
Table 2. Number of patients with spinal stenosis at each spinal level

\begin{tabular}{|c|c|c|c|c|c|c|c|c|c|}
\hline \multirow[b]{2}{*}{ Level } & \multicolumn{4}{|c|}{ Satisfied group (n=128) } & \multicolumn{4}{|c|}{ Dissatisfied group ( $\mathrm{n}=29$ ) } & \multirow[b]{2}{*}{$p$-value } \\
\hline & $\begin{array}{c}\text { Minor } \\
\text { stenosis }\end{array}$ & $\begin{array}{c}\text { Moderate } \\
\text { stenosis }\end{array}$ & $\begin{array}{c}\text { Severe } \\
\text { stenosis }\end{array}$ & $\begin{array}{l}\text { Extreme } \\
\text { stenosis }\end{array}$ & $\begin{array}{c}\text { Minor } \\
\text { stenosis }\end{array}$ & $\begin{array}{c}\text { Moderate } \\
\text { stenosis }\end{array}$ & $\begin{array}{l}\text { Severe } \\
\text { stenosis }\end{array}$ & $\begin{array}{l}\text { Extreme } \\
\text { stenosis }\end{array}$ & \\
\hline L1-L2 & 115 & 12 & 1 & 0 & 24 & 3 & 2 & 0 & 0.21 \\
\hline $\mathrm{L} 2-\mathrm{L} 3$ & 100 & 17 & 10 & 1 & 17 & 9 & 3 & 0 & 0.12 \\
\hline L3-L4 & 61 & 42 & 23 & 2 & 14 & 6 & 6 & 3 & 0.25 \\
\hline L4-L5 & 52 & 22 & 47 & 7 & 13 & 4 & 10 & 2 & 0.82 \\
\hline L5-S1 & 120 & 6 & 2 & 0 & 28 & 1 & 0 & 0 & 0.36 \\
\hline
\end{tabular}

Data were analyzed using Pearson's chi-square test.

Table 3. Comparison of clinical outcomes between satisfied and dissatisfied groups at 6 months postoperatively

\begin{tabular}{|c|c|c|c|c|c|c|}
\hline \multirow{2}{*}{ Variable } & \multicolumn{3}{|c|}{ At 6 months } & \multicolumn{2}{|c|}{ Mean change at 6 months } & \multirow{2}{*}{$\begin{array}{c}\begin{array}{c}\text { Difference between } \\
\text { groups }\end{array} \\
\begin{array}{c}\text { Satisfied minus } \\
\text { dissatisfied group }\end{array}\end{array}$} \\
\hline & $\begin{array}{l}\text { Satisfied group } \\
\qquad(\mathrm{n}=128)\end{array}$ & $\begin{array}{l}\text { Dissatisfied group } \\
\qquad(\mathrm{n}=29)\end{array}$ & $p$-value & $\begin{array}{l}\text { Satisfied group } \\
\qquad(\mathrm{n}=128)\end{array}$ & $\begin{array}{l}\text { Dissatisfied group } \\
\qquad(\mathrm{n}=29)\end{array}$ & \\
\hline \multicolumn{7}{|l|}{$\mathrm{ZCO}$} \\
\hline Symptom severity & $2.4 \pm 0.7$ & $3.5 \pm 0.6$ & $0.00^{\mathrm{al}}$ & $-1.1(-1.3$ to -1.0$)$ & $-0.2(-0.3$ to 0$)$ & $-1.0(-1.4$ to -0.7$)$ \\
\hline Physical function & $1.7 \pm 0.6$ & $2.6 \pm 0.6$ & $0.00^{b)}$ & $-0.9(-1.0$ to -0.8$)$ & $-0.1(-0.3$ to 0$)$ & $-0.8(-1.0$ to -0.5$)$ \\
\hline Satisfaction & $1.7 \pm 0.4$ & $3.2 \pm 0.4$ & $0.00^{\mathrm{bl}}$ & & & \\
\hline \multicolumn{7}{|l|}{ VAS } \\
\hline Back pain & $32.0 \pm 28.2$ & $52.6 \pm 24.4$ & $0.00^{b)}$ & $-28.8(-35.1$ to -22.4$)$ & $-3.3(-16.4$ to 9.9$)$ & $-25.5(-40.3$ to -10.7$)$ \\
\hline Leg pain & $32.1 \pm 28.8$ & $61.9 \pm 24.8$ & $0.00^{\mathrm{bl}}$ & $-36.5(-43.0$ to -30.0$)$ & $-5.1(-15.9$ to 5.6$)$ & $-34.0(-48.7$ to -19.4$)$ \\
\hline Leg numbness & $33.7 \pm 29.6$ & $64.0 \pm 23.6$ & $0.00^{\mathrm{bl}}$ & $-28.2(-34.8$ to -21.6$)$ & $-2.3(-14.1$ to 9.6$)$ & $-28.1(-42.9$ to -13.3$)$ \\
\hline \multicolumn{7}{|l|}{ JOABPEQ-acquired points } \\
\hline Pain-related disorders & & & & 36.6 (30.5 to 42.7$)$ & $2.4(-11.5$ to 16.2$)$ & $33.9(19.7$ to 18.2$)$ \\
\hline Lumbar dysfunction & & & & 14.2 (8.6 to 19.9$)$ & $-16.3(-29.5$ to 3.1$)$ & $30.0(17.0$ to 42.9$)$ \\
\hline Gait disturbance & & & & 41.9 (36.8 to 47.1$)$ & $3.8(-7.1$ to 14.7$)$ & 38.1 (26.1 to 50.1$)$ \\
\hline Social life dysfunction & & & & 26.1 (21.8 to 30.3) & $-26.3(-13.1$ to 0.4$)$ & 32.8 (23.3 to 42.2 ) \\
\hline Psychological disorders & & & & 15.4 (12.5 to 18.3$)$ & $-2.9(-9.7$ to 3.8$)$ & $18.7(11.7$ to 25.6$)$ \\
\hline \multicolumn{7}{|l|}{ SF-36 } \\
\hline Physical functioning & $69.0 \pm 22.2$ & $42.8 \pm 20.3$ & $0.00^{\mathrm{bl}}$ & 24.0 (19.9 to 28.1) & $-1.3(-8.8$ to 6.1$)$ & 25.3 (16.1 to 34.6$)$ \\
\hline Bodily pain & $62.3 \pm 21.5$ & $33.0 \pm 14.6$ & $0.00^{\mathrm{bl}}$ & $31.3(27.0$ to 35.6$)$ & $5.1(-2.0$ to 12.2$)$ & 26.2 (16.6 to 35.9$)$ \\
\hline Role physical & $61.2 \pm 27.3$ & $33.1 \pm 24.1$ & $0.00^{\mathrm{bl}}$ & 20.5 (15.3 to 25.7) & $-6.0(-15.1$ to 3.0$)$ & $26.0(14.0$ to 38.0$)$ \\
\hline Role emotional & $68.0 \pm 27.8$ & $35.4 \pm 28.6$ & $0.00^{\mathrm{bl}}$ & $18.9(12.9$ to 24.9$)$ & $-1.8(-13.4$ to 9.8$)$ & $20.5(6.9$ to 34.1$)$ \\
\hline Mental health & $73.3 \pm 18.0$ & $48.9 \pm 20.3$ & $0.00^{b)}$ & 13.5 (10.0 to 16.9$)$ & $2.0(-5.4$ to 9.3$)$ & 11.5 (3.6 to 19.3$)$ \\
\hline Social functioning & $77.9 \pm 23.8$ & $50.9 \pm 26.1$ & $0.00^{b)}$ & 16.6 (10.9 to 22.3) & $-6.3(-15.6$ to 3.1$)$ & 22.5 (14.0 to 38.0$)$ \\
\hline Vitality & $64.3 \pm 18.6$ & $37.7 \pm 19.6$ & $0.00^{b)}$ & $15.3(11.0$ to 19.6$)$ & $-2.8(-10.5$ to 4.8$)$ & 18.1 (8.4 to 27.9) \\
\hline General health & $58.0 \pm 16.9$ & $44.4 \pm 13.5$ & $0.00^{\mathrm{bl}}$ & $8.0(5.0$ to 11.0$)$ & $1.6(-4.8$ to 8.0$)$ & $6.4(-0.4$ to 13.3$)$ \\
\hline
\end{tabular}

Values are presented as mean \pm standard deviation or odds ratio (95\% confidence interval).

ZCQ, Zurich Claudication Questionnaire; VAS, Visual Analog Scale; JOABPEQ, Japanese Orthopaedic Association Back Pain Evaluation Questionnaire; SF-36, Medical Outcomes Study 36-Item Short-Form General Health Survey.

${ }^{a}$ By Student $t$-test. ${ }^{b}$ By Mann-Whitney $U$-test. 
Table 4. Logistic regression models of baseline factors that predicted patient dissatisfaction at 6 months postoperatively

\begin{tabular}{|c|c|c|}
\hline Baseline factor & $\begin{array}{c}\text { Odds ratio } \\
\text { (95\% confidence interval) }\end{array}$ & $p$-value \\
\hline VAS low back pain $\geq$ median (68.5) & $0.27(0.10-0.74)$ & 0.01 \\
\hline SF-36 mental health $\geq$ median (55.0) & $0.26(0.08-0.89)$ & 0.03 \\
\hline HADS anxiety $\geq$ median (5.0) & $3.95(1.16-13.46)$ & 0.03 \\
\hline
\end{tabular}

The independent variables entered into model were age, gender, body mass index, presence of comorbidities, smoking status, duration of symptoms, surgical procedure, predominance of back pain, Zurich Claudication Questionnaire, VAS, Japanese Orthopaedic Association Back Pain Evaluation Questionnaire, SF-36, HADS, Pain Catastrophizing Scale, and Pain Anxiety Symptoms Scale. Nagelkerke's $R^{2}=0.26$. Hosmer-Lemeshow goodness-of-fit test $=0.53$. VAS, Visual Analog Scale; SF-36, Medical Outcomes Study 36-Item Short-Form General Health Survey; HADS, Hospital Anxiety and Depression Scale.

significantly and converged with scores for nondepressed patients 12 months after surgery. Sinikallio et al. [28] reported that patients with continuous depression after LSS surgery showed less improvement in ZCQ symptom severity, ODI score, pain intensity, and walking capacity than patients who did not experience depression at any phase. Therefore, preoperative depression may not always be associated with patient satisfaction and poor surgical outcome as it may improve after surgery. Furthermore, the level of depression in our patients might have been lower compared with the level in the patients in previous studies because we excluded patients with a history of psychiatric illness. The preoperative mean HADS depression subscale score in the dissatisfied group was 7.0 points, which is less than the cutoff for doubtful cases (8.0 points). It is noteworthy that anxiety was associated with dissatisfaction in patients without a history of psychiatric illness but not depression.

Although the dissatisfied group had higher levels of magnification on the PCS before surgery, preoperative catastrophizing and fear-avoidance beliefs measured by the PASS-20 were not prognostic factors for patient satisfaction. Kim et al. [15] reported no differences in ODI scores and VAS scores for back and leg pain between patients with low and high preoperative PCS scores at 12 months after LSS surgery. Coronado et al. [16] found that increased pain catastrophizing at 6 weeks after lumbar degenerative spine surgery is associated with having persistent back pain intensity, pain interference, and disability. Regarding fear-avoidance beliefs, Archer et al. [29] found that postoperative but not preoperative fear of movement beliefs, as measured by the Tampa Scale for Kinesiophobia, explained the unique and significant variance in postoperative pain, disability, and physical health in patients treated with surgery for lumbar and cervical degenerative conditions. Similarly, Burgstaller et al. [17] found that preoperative fear-avoidance beliefs, as measured by the Fear-Avoidance Beliefs Questionnaire, was not a prognostic factor for outcome in elderly patients undergoing LSS decompression surgery; however, patients with fear-avoidance beliefs at 6 months and persistent fear-avoidance beliefs were less likely to experience clinically relevant pain improvement at 12 months. Our findings are consistent with these, even though we used another instrument (PASS-20) to assess fear-avoidance beliefs. Postoperative catastrophizing and fear-avoidance beliefs are more likely to be associated with postoperative satisfaction and outcome than preoperative beliefs.

Less severe low back pain before surgery was associated with poor satisfaction in our study. However, a previous study found that back pain predominance (back pain more severe than leg pain) is associated with lower patient satisfaction after LSS surgery [6]. Although back pain predominance was an independent variable in our multivariate logistic regression analysis, no association with satisfaction was found. Furthermore, the degree of improvement in back pain after lumbar spine surgery has been reported to reflect patient satisfaction [30]. Therefore, it seems that patients with severe low back pain are more likely to obtain postoperative satisfaction.

Preoperative psychological factors assessed by the PCS and HADS in patients with LSS are associated with preoperative ZCQ, JOABPEQ, and Roland-Morris Disability Questionnaire scores [31]. In our study, severity of LSS symptoms before surgery as assessed by the ZCQ and JOABPEQ did not differ between satisfied and dissatisfied patients. Although preoperative psychological distress was associated with preoperative symptom severity, only preoperative anxiety was associated with satisfaction and affected clinical outcome, not depression and pain catastrophizing. Therefore, assessing and managing anxiety before surgery may improve surgical results. However, postoperative psychological distress appears to be associated with postoperative outcome as well $[16,17,28,29]$. Postoperative psychological status should also be carefully assessed and appropriately managed to obtain optimal surgical results.

Our study has several limitations. The sample size was relatively small, especially in the dissatisfied group, which 
limits statistical rigor. In addition, we included patients who underwent decompression with and without fusion; although type of surgical procedure was not associated with patient satisfaction, different pathologies might have affected pre- and postoperative psychological status. Moreover, the 6-month follow-up period was insufficient to fully evaluate surgical outcome, especially in patients who underwent fusion surgery. However, we believe short-term outcomes are important, because they can help guide appropriate rehabilitation programs for patients who do not respond to surgery and decrease the total cost of treatment. Finally, we did not use the HADS, PCS, and PASS-20 to assess postoperative psychological status because our primary aim was to identify preoperative psychological factors associated with patient satisfaction. Future studies should focus on postoperative psychological status.

\section{Conclusions}

Patients dissatisfied with LSS surgery showed no improvement in patient-reported measures of pain, disability, and quality of life 6 months after surgery. Preoperative low back pain, mental health, and anxiety were associated with patient dissatisfaction, but not depression, pain catastrophizing, and fear-avoidance beliefs. These findings suggest that pre- and postoperative psychological status should be carefully assessed and appropriately managed to improve clinical results after surgery for LSS.

\section{Conflict of Interest}

No potential conflict of interest relevant to this article was reported.

\section{ORCID}

Yoshio Yamamoto: https://orcid.org/0000-0002-8978-5865; Mamoru Kawakami: https://orcid.org/0000-0002-2182-3132; Masakazu Minetama: https://orcid.org/0000-0001-9906-9224; Masafumi Nakagawa: https://orcid.org/0000-0002-0875-8807; Masatoshi Teraguchi: https://orcid.org/0000-0003-4578-0656; Ryohei Kagotani: https://orcid.org/0000-0002-0973-732X; Sachika Matsuo: https://orcid.org/0000-0002-9211-8377

\section{Author Contributions}

Conception and design: Yoshio Yamamoto, Mamoru Kawakami, Masakazu Minetama, Yukihiro Nakagawa; data acquisition: Masafumi Nakagawa, Masatoshi Teraguchi, Ryohei Kagotani, Yoshimasa Mera, Tadashi Sumiya, Sachika Matsuo, Tomoko Kitano; analysis of data: Yoshio Yamamoto, Masakazu Minetama, Tomoko Kitano; drafting of the manuscript: Yoshio Yamamoto; critical revision and administrative support: Mamoru Kawakami, Masakazu Minetama, Masafumi Nakagawa, Masatoshi Teraguchi, Ryohei Kagotani, Yoshimasa Mera, Tadashi Sumiya, Sachika Matsuo, Tomoko Kitano, Yukihiro Nakagawa; and supervision: Mamoru Kawakami, Yukihiro Nakagawa.

\section{References}

1. Katz JN, Harris MB. Clinical practice: lumbar spinal stenosis. N Engl J Med 2008;358:818-25.

2. Deyo RA. Treatment of lumbar spinal stenosis: a balancing act. Spine J 2010;10:625-7.

3. Hara N, Oka H, Yamazaki T, et al. Predictors of residual symptoms in lower extremities after decompression surgery on lumbar spinal stenosis. Eur Spine J 2010;19:1849-54.

4. Paulsen RT, Bouknaitir JB, Fruensgaard S, Carreon L, Andersen M. Prognostic factors for satisfaction after decompression surgery for lumbar spinal stenosis. Neurosurgery 2018;82:645-51.

5. Sanden B, Forsth P, Michaelsson K. Smokers show less improvement than nonsmokers two years after surgery for lumbar spinal stenosis: a study of 4555 patients from the Swedish spine register. Spine (Phila Pa 1976) 2011;36:1059-64.

6. Sigmundsson FG, Jonsson B, Stromqvist B. Determinants of patient satisfaction after surgery for central spinal stenosis without concomitant spondylolisthesis: a register study of 5100 patients. Eur Spine J 2017;26:473-80.

7. Knutsson B, Michaelsson K, Sanden B. Obesity is associated with inferior results after surgery for lumbar spinal stenosis: a study of 2633 patients from the Swedish spine register. Spine (Phila Pa 1976) 2013;38:435-41.

8. Radcliff KE, Rihn J, Hilibrand A, et al. Does the duration of symptoms in patients with spinal stenosis and degenerative spondylolisthesis affect outcomes?: 
analysis of the Spine Outcomes Research Trial. Spine (Phila Pa 1976) 2011;36:2197-210.

9. Aalto TJ, Malmivaara A, Kovacs F, et al. Preoperative predictors for postoperative clinical outcome in lumbar spinal stenosis: systematic review. Spine (Phila Pa 1976) 2006;31:E648-63.

10. Leeuw M, Goossens ME, Linton SJ, Crombez G, Boersma K, Vlaeyen JW. The fear-avoidance model of musculoskeletal pain: current state of scientific evidence. J Behav Med 2007;30:77-94.

11. Merrill RK, Zebala LP, Peters C, Qureshi SA, McAnany SJ. Impact of depression on patient-reported outcome measures after lumbar spine decompression. Spine (Phila Pa 1976) 2018;43:434-9.

12. Dobran M, Nasi D, Gladi M, et al. Clinical and psychological outcome after surgery for lumbar spinal stenosis: a prospective observational study with analysis of prognostic factors. Neurol Neurochir Pol 2018;52:70-4.

13. Lee J, Kim HS, Shim KD, Park YS. The effect of anxiety, depression, and optimism on postoperative satisfaction and clinical outcomes in lumbar spinal stenosis and degenerative spondylolisthesis patients: cohort study. Clin Orthop Surg 2017;9:177-83.

14. Kitano Cp T, Kawakami M, Fukui D, et al. Preoperative psychological factors affecting surgical satisfaction of elderly patients with lumbar spinal stenosis. J Orthop Sci 2020;25:751-6.

15. Kim HJ, Park JW, Chang BS, Lee CK, Yeom JS. The influence of catastrophizing on treatment outcomes after surgery for lumbar spinal stenosis. Bone Joint J 2015;97-B:1546-54

16. Coronado RA, George SZ, Devin CJ, Wegener ST, Archer KR. Pain sensitivity and pain catastrophizing are associated with persistent pain and disability after lumbar spine surgery. Arch Phys Med Rehabil 2015;96:1763-70.

17. Burgstaller JM, Wertli MM, Steurer J, et al. The influence of pre- and postoperative fear avoidance beliefs on postoperative pain and disability in patients with lumbar spinal stenosis: analysis of the Lumbar Spinal Outcome Study (LSOS) data. Spine (Phila Pa 1976) 2017;42:E425-32.

18. Hara N, Matsudaira K, Masuda K, et al. Psychometric assessment of the Japanese version of the Zurich Claudication Questionnaire (ZCQ): reliability and validity. PLoS One 2016;11:e0160183.
19. Fukui M, Chiba K, Kawakami M, et al. Japanese Orthopaedic Association Back Pain Evaluation Questionnaire. Part 3. Validity study and establishment of the measurement scale: Subcommittee on Low Back Pain and Cervical Myelopathy Evaluation of the Clinical Outcome Committee of the Japanese Orthopaedic Association, Japan. J Orthop Sci 2008;13:1739.

20. Fukuhara S, Ware JE Jr, Kosinski M, Wada S, Gandek B. Psychometric and clinical tests of validity of the Japanese SF-36 Health Survey. J Clin Epidemiol 1998;51:1045-53.

21. Kitamura M. Hospital Anxiety and Depression Scale. Q Psychiatr Diagn 1993;4:371-2.

22. Matsuoka H, Sakano Y. Assessment of cognitive aspect of pain: development, reliability, and validation of Japanese version of pain catastrophizing scale. Jpn J Psychosom Med 2007;47:95-102.

23. Matsuoka H, Sakano Y. Development and validation of Japanese version of pain anxiety symptoms scale-20. Jpn J Behav Med 2008;14:1-7.

24. Schizas C, Theumann N, Burn A, et al. Qualitative grading of severity of lumbar spinal stenosis based on the morphology of the dural sac on magnetic resonance images. Spine (Phila Pa 1976) 2010;35:191924.

25. Mirza SK, Deyo RA, Heagerty PJ, et al. Development of an index to characterize the "invasiveness" of spine surgery: validation by comparison to blood loss and operative time. Spine (Phila Pa 1976) 2008;33:265162.

26. Ng LC, Tafazal S, Sell P. The effect of duration of symptoms on standard outcome measures in the surgical treatment of spinal stenosis. Eur Spine J 2007;16:199-206.

27. Wagner A, Shiban Y, Wagner C, et al. Psychological predictors of quality of life and functional outcome in patients undergoing elective surgery for degenerative lumbar spine disease. Eur Spine J 2020;29:34959.

28. Sinikallio S, Aalto T, Airaksinen O, et al. Depression is associated with poorer outcome of lumbar spinal stenosis surgery. Eur Spine J 2007;16:905-12.

29. Archer KR, Wegener ST, Seebach C, et al. The effect of fear of movement beliefs on pain and disability after surgery for lumbar and cervical degenerative conditions. Spine (Phila Pa 1976) 2011;36:1554-62. 
30. Crawford CH 3rd, Carreon LY, Bydon M, Asher AL, Glassman SD. Impact of preoperative diagnosis on patient satisfaction following lumbar spine surgery. J Neurosurg Spine 2017;26:709-15.
31. Kitano T, Kawakami M, Ishimoto Y, et al. Psychological distress associated with patient-reported outcomes in preoperative patients with lumbar spinal stenosis. Asian Spine J 2020 Sep 3 [Epub]. https://doi.org/10.31616/asj.2020.0093. 